\title{
On Some Features of Logical Thought in Writing
}

\author{
Marina Karapetyan \\ Yerevan State University
}

\begin{abstract}
This paper considers some features of logical thinking in persuasive essay writing. A solid essay is logically organized and well-developed; it advances consistent arguments supported by strong evidence. At the same time, it demonstrates cogency of reasoning, completeness and unity of thought. All this suggests that the ideas in each paragraph and the overall essay relate to one another, are arranged in a logical sequence and lead to a valid conclusion. Based on scientific approach to logical reasoning, the paper outlines various reasoning techniques that can be employed to produce a forceful essay.
\end{abstract}

Key words: logical sequence, deduction, induction, analogy, causal argument, predictions, credibility.

\section{Introduction}

Teaching how to write an independent essay is more than just explaining how to brainstorm, plan and put ideas on paper. It also aims at making the writer's ideas more orderly, rational and cohesive. In the 30 or 40 minutes of allotted writing time on the TOEFL IBT and IELTS tests, it is hard for a foreign language learner (even at an intermediate and an upper-intermediate level) to integrate new language skills with logical thinking. As a result, we deal with works which are rather incomprehensible due to abrupt changes of thought, cluttered ideas, errors of judgement and invalid conclusions.

This paper considers some features of logical thinking in persuasive essay writing for the TOEFL IBT and IELTS tests. A solid essay is logically organized and well-developed; it advances consistent arguments supported by strong evidence. At the same time, it demonstrates cogency of reasoning, completeness and unity of thought. Based on scientific approach to logical reasoning, the paper outlines various reasoning techniques that can be employed 
to produce a forceful essay. Paragraphs used to illustrate the techniques are borrowed both from model and students' essays.

\section{Essay Logic}

Logical reasoning is an effective method of persuasion which makes the author's ideas easy to follow. The essay writer seeks to appeal to reason by using logical arguments to communicate to the reader the way s/he understands an issue. Admittedly, opinions vary from person to person and hence should be supported by sound reasons. In this process, the writer advances several evidence-based arguments and proceeds toward a justified conclusion. Although test-takers are not judged for wrong opinions, it is a distinct advantage to be able to demonstrate rational thinking. What they need is to express themselves in a logically consistent way so the essay reads smoothly and the ideas are readily comprehensible.

On this background, the essay logic serves two functions: correlating the premises and the conclusion, on the one hand, and assessing the degree of plausibility of the conclusion, on the other. The former rests on the arrangement of ideas in a certain sequence, while the latter consists in the writer's ability to employ deductive and inductive reasoning techniques, including enumerative induction, analogical induction, causal arguments and predictions. The combination of the two methods strengthens the writer's arguments and prevents potential weaknesses. Further, we shall consider them more closely.

\section{Correlating the Premises and the Conclusion}

In terms of correlation of the premises and the conclusion, two broad types of idea progression in an essay can be categorized: from a general point to particular information and vice versa.

When we examine model essays from various sources, what we observe is that most writings apply general-to-specific order, although it is not rare to find good examples of the reverse sequence. The process is slightly different in an overall essay and in body paragraphs. In an overall essay, the information is sequenced from the general thesis statement to supporting evidence. The thesis in the introductory paragraph expresses the writer's position on an issue and is followed by three or four body paragraphs presenting more concrete ideas to bring credibility to the thesis. The conclusion to be reached is predictable - the reader can anticipate the outcome from the earlier stated thesis. 
Thus, a short plan for a general-to-specific essay looks as follows:

Thesis: Children's new habits are the source of their poor health.

Para 1: Too much homework causes stress and exhaustion.

Para 2: Violent computer games make children nervous.

Para 3: Junk food and lack of exercise lead to obesity and related illnesses.

Conclusion: Children's bad habits are a serious threat to growing organisms.

As can be seen, the writer adopts a general attitude about an issue and then seeks to reinforce it by outlining specific evidence. The conclusion confirms the initial thesis.

Alternatively, in a body paragraph the order is from the topic sentence to specific details and examples. The topic sentence in each paragraph sets forth one basic argument (the main idea), the explanation clarifies its meaning, and the details illustrate the point. In fully developed paragraphs this information is also emphasized in a closing sentence, which gives the paragraph a sense of unity and completeness. Consider the paragraph below:

Many people would not endure work they hate, whatever the external benefits. Passion for what one does gives an intrinsic stimulus to succeed. This is especially true of people of creative professions such as painters, musicians, beauticians, actors, as well as people engaged in scientific activity. An inventor puts his heart and soul into his brainchild without thinking about the profits he can get from it. The best reward for him is to see the humanity enjoying his creation. Love for one's job is what really matters.

Because the conventional general-to-specific pattern keeps to a fixed plan, it is the easy to teach and to learn. It is also the most effective and practical form of logical organization: the essay is comprehensible and focused, the train of thought is easy to follow, and the conclusion can be predicted. It is helpful for producing various kinds of essays, including argumentative, cause-and-effect, compare-and-contrast, problem-solution and descriptive ones. 
The other mode of writing an essay follows a specific-to-general order. This is a less common strategy and is favored by writers who are ready to experiment in the writing process. Using creative and unorthodox thinking, they organize their ideas by drawing on specific occurrences as springboards from which to move to general statements. The essay's thesis statement is given in the introduction only as a preliminary observation, which may be slightly modified by the end of the writing process. In turn, the topic ideas come in the body paragraphs preceded by examples and details.

The student's paragraph below demonstrates the use of specific-to-general order (Question: Some people say that advertising encourages us to buy things we really do not need. Others say that advertisements tell us about new products that may improve our lives. Which viewpoint do you agree with?):

To begin with, when we see the radiant smile of an actress who supposedly washes her teeth with Colgate, for example, we are subconsciously urged to buy the toothpaste. We want to believe that our teeth will shine as brightly as hers. Advertising agencies use psychological means of persuasion: nice-looking happy people, promise of solutions for all our problems, etc. Truly, ads reach their goal of persuading us we can't do without certain goods and services.

The writer arrives at his conclusion resting on the example of a particular advert and on the response this and other ads evoke in the audience.

Below is another example, which is abridged from a model essay (Official TOEFL IBT Tests, 2013, TOEFL Test Prep Planner: 73). The specific-togeneral order is used throughout the essay (Question: Do you agree or disagree? A teacher's ability to relate well with students is more important than excellent knowledge of the subject being taught):

I remember every teacher that has taught me since I was in Kindergarten. ........ The teachers all looked very kind and understanding in my eyes as a child. They had special relationships with nearly each and every one of the students. That's the reason I remember all of them.

A teacher's primary goal is to teach students the best they can 
about the things that are in our textbooks and, more important, how to show respect for one another. They teach us how to live a better life by getting along with everyone. In order to do that, the teachers themselves have to be able to relate well with students.

My parents are teachers too. ......... My parents' ability to relate well with my brother and I allows them to teach not just the subject they teach but also their excellent knowledge of life.

Knowledge of the subject being taught is something taken for granted. ......... Any teacher is able to have excellent knowledge of their subject but not all teachers can have the ability to relate well with students.

As can be seen, the writer proceeds from his personal school experience, as well as his relations with his own parents, who are also teachers. He establishes his priorities at the end of each paragraph and fully exposes his belief about a teacher's most important quality in the closing lines.

What is especially interesting about this mode of writing is that you can end up with an unexpected conclusion. The writer is primarily guided by some specific instances from his or her life, and it is those instances that dictate the direction the essay will develop further. In fact, the results can be unpredictable and the writer can easily digress from his or her purpose. The method is mainly applicable to scientific research but it can also be effective in expository, descriptive and other types of short essay and is certainly worth practicing if one has a passion for writing and creative potential.

There have not been too many student essays in our practice that used purely specific-to-general organization, although a few test-takers have well succeeded in developing their essays in this way. On the whole, the pattern can be seen more frequently on a paragraph level, especially in the conclusion. By contrast, an overall essay typically applies the reverse pattern.

\section{Assessing the Degree of Plausibility of the Conclusion}

The two aforesaid methods of sequencing ideas also indicate the so-called deductive and inductive logical reasoning, respectively. However, these reasoning processes imply more than just putting ideas in order. At this point, we arrive at the other logical function - assessing the degree of plausibility of the conclusion. In this sense, some arguments lead to "necessary" conclusions, 
others to "credible" ones. The former arguments are sufficient to lead to only one possible conclusion with no other alternatives. The latter arrive at a conclusion only with some degree of certainty. According to the degree of plausibility of the conclusion, two main types of arguments can be distinguished: deductive and inductive.

In independent essays a conclusion that is absolutely true is a rare case. Thus, we can only be speaking about credible conclusions. The analysis of a substantial number of model and students' essays leads us to the inference that even though most persuasive writings are organized deductively in terms of idea progression (general-to-specific), not all of them can be claimed to be deductive in the sense that the conclusion is not reached with absolute certainty. In case of deductive reasoning, however, the degree of plausibility is a matter of a claim's scope, whereas induction always leaves room for speculation.

Let us consider a model deductive paragraph:

Career preparation is becoming more and more important to young people. For many, this is the primary reason to go to college. They know that the job market is competitive. At college, they can learn new skills for careers with a lot of opportunities. This means careers, such as information technology, that are expected to need a large workforce in the coming years.

(Lougheed 2004:150)

To make the argument easy to follow, we have adapted it to a simple deductive syllogism (in this case, the so-called hypothetical syllogism):

Major premise: If some young people go to college, they will learn new skills.

Minor premise: If they learn new skills, they will have careers with a lot of opportunities, such as information technology.

Conclusion: If some young people go to college, they will have careers with a lot of opportunities, such as information technology.
If $\mathrm{A}$ then $\mathrm{B}$.

If $\mathrm{B}$ then $\mathrm{C}$.

Therefore, if A then C. 
Here, the writer takes a position on an issue and tries to justify her point of view. As can be seen, the given premises are quite sufficient to come to a sound and necessary conclusion, if we consider that the claim is limited to "many" or "some" young people. If a full scope claim were made, using words like "all", "everyone", "students" in general, or adverbs like "always", the conclusion would have a considerable degree of uncertainty.

In turn, inductive arguments only lead to credible rather than necessary conclusions. With the focus on writing TOEFL and IELTS essays, we shall limit our discussion to four of the major types of inductive reasoning: enumerative induction, analogical induction, causal arguments, and predictions. In the so-called enumerative induction, we base our judgements about the entire class on the observation of a limited number of subjects from the same class. As a case in point, consider the above essay from ETS where the writer describes the teaching methods of his parents thus arriving at the conclusion that a teacher's most important quality is the ability to relate well with students rather than the excellent knowledge of the subject taught. This conclusion cannot be viewed as certain or necessary, at least because it is an example of the teachers' ability to relate well with one's own children - an extremely limited scope for judging about the same ability at large. We cannot accurately judge about all teachers even resting on the writer's relationships with other teachers in his life.

Enumerative induction in short essays is also reflected by statistical reasoning, where the writer judges about all by answers taken from a representative sample, which cannot indicate facts with absolute accuracy. On the test, it is rare to use statistics as it does not readily come to mind. Yet, it is not impossible, and students with certain professional backgrounds sometimes provide relevant numerical data.

Another type of inductive argument is analogical induction. It is based on a comparison of different objects or phenomena. The writer seeks to describe or explain the qualities of one object resting on its essential similarities with the other. Similarities in a number of characteristics suggest that the objects are likely to share other characteristics too. The degree of plausibility of the conclusions depends on the correlation of similarities and differences between the objects compared. The more the objects are alike, the higher the probability of the conclusion, and vice versa. Analogies create memorable mental images and thus help both the writer and the reader visualize an issue. But they are only 
used to clarify a hypothesis rather than prove it. This kind of reasoning predominantly occurs on a sentence and paragraph levels.

In his essay, one student drew a conclusion that social networks can replace face-to-face communication. He proceeded from an analogical argument that on social networks one can meet real people, follow their life events, comment on their activity, share interests, seek and offer advice - the same things friends do in real life. Quite rational, at first sight - especially if we are only speaking about communication, not true friendship. This conclusion, though not the only possible one, has a high degree of probability.

Consider a paragraph from another student's essay (Question: Do you agree or disagree? Disobedient students must be isolated from the rest of the class and taught separately):

Trying to teach a student who isn't willing to learn is the same as trying to treat a patient who is indifferent to his own health. Like the patient who can't be cured if he is not willing to take the medicine prescribed by his doctor, the student who is too lazy to follow his teacher's instructions will not be able to succeed. Alternatively, even if a hopeless patient eventually starts the treatment, his apathy will impede his recovery. This is also true of a student who is only motivated to learn because of the upcoming exam. Without internal motivation he will not make progress.

Despite the strong impression they leave on a reader, analogies can be somewhat faulty. Some relevant similarities between the compared subjects may really exist, but the conclusion will always have a degree of uncertainty. We cannot judge about all students by their broad similarity with patients. Moreover, the student who is lazy to follow his teacher's instructions may be quite willing to learn very effectively on his own. Similarly, the patient opposing the doctor's prescriptions may be a supporter of alternative medicine and be getting effective treatment from an acupuncturist. Take another analogy: A good roommate is someone who could replace your parent, a sister, a bosom friend. This one is faulty because the seeming resemblance fails at the point we think more closely and see that however perfect a roommate might be, s/he would hardly ever replace a parent. It is important to keep in mind that "analogies cannot serve as evidence in a rational argument because the 
differences always outweigh the similarities; but analogies can reinforce such arguments if the subjects are indeed similar in some ways" (Kennedy et al 2003:509).

Another type of inductive argument is causal or cause-and-effect reasoning (also referred to as "scientific induction"). In a causal relationship one phenomenon or event is claimed to be the cause of the other, or vice versa. The two premises of the argument are referred to as cause/reason and effect/result. As different from applying this argument in scientific research, in developing it for a test essay we are not seeking for real, but rather possible, causes or effects. Thus, the conclusion reached is only credible, not necessary. Nevertheless, the causal argument is considered to be stronger than the previous two types of induction and has a higher degree of plausibility of the conclusion.

This essay layout presents the possible causes why people are living longer now:

Argument: Today, people are enjoying better health and have longer life expectancy than in the past.

Cause 1: Healthcare services and technologies have developed in recent years.

Cause 2: Life conditions have become more comfortable.

Cause 3: People are more health-conscious today.

Conclusion (= effect): Today, people are able to live healthier and longer lives.

The other layout below outlines the effects of building a new factory in a community. The prompt requires discussing both the advantages and disadvantages of this new influence and expressing one's attitude about the issue.

Argument (= cause): Building a new factory in our small town will bring more problems than benefits.

Effect 1: It will ruin the ancient architecture of the town.

Effect 2: It will pollute our environment and entail new health risks.

Effect 3: A new factory will create many job openings. 
Conclusion: The drawbacks of a new factory outweigh the benefits, so I am against its construction.

There are probably numerous other factors that might prolong life and factors that building a new factory might result in, but it is quite possible to reach a higher plausibility of conclusion by narrowing the scope to major factors only, which should be carefully weighed in terms of their likelihood and correlation with the issues discussed.

The last reasoning technique we would like to discuss is prediction. Here the writer proceeds from the present or past events to make judgements about the future prospects. Although the conclusion is not definite or inevitable, it is highly probable.

In the example below, a student pictures some of the changes the $21^{\text {st }}$ century may bring. His argument about the future is based on the past and present evidence:

I envisage there will be multiple accomplishments in the sphere of technologies. Judging by the pressing current issues, most of the upcoming global innovations in this century will be aimed at reducing environmental risks. For example, greener fuels will be used on a larger scale to drive automobiles, run factories, and warm our dwellings. Besides, some countries are already using costly technology for producing home appliances like refrigerators. This technology prevents ozone depletion. I think after a while this technology will also be available in poor countries.

We have demonstrated how helpful logical reasoning can be if used correctly. At the same time, all types of logical arguments are prone to fallacies. Further, we shall briefly consider the fallacies that occur most frequently in our students' essays.

\section{Reasoning Fallacies}

Among the typical reasoning errors are the so called false causes and false effects. As a case in point, the following relationship reveals a false effect: Due to the development of medical technology, many diseases can be healed today. 
$\rightarrow$ Technologies make our world a safer place to live. The fact that diseases can already be healed doesn't make the world a safe place. Diseases still exist, even though they have become curable. The argument would sound more truthful and logical if diseases had been eradicated or reduced due to technological advances.

Similarly, the following ideas are obviously unrelated: Nothing can be compared to the taste of the Armenian apricot. $\rightarrow$ For this reason, ancient Romans called this fruit an "Armenian apple." A question naturally arises here. How could Romans liken the apricot to the apple or any other fruit if the taste of the former is unmatched or unrivalled?

The argument below reflects a false cause-and-effect relationship. It occurred as a result of breaking the rules of the deductive syllogism:

Major premise: People in the past had fewer health problems than today.

Minor premise: In the past there were no computers.

Conclusion: Without computers people would be healthier.

Even if we consider the two premises as true, the conclusion should not necessarily be true. The fact that computers are the reason for poor health cannot be deduced from the two given premises. The argument is unsound.

Another common error is referred to as begging the question, when the writers "repeat what they already believe, only in different words" (Kennedy et al, 2003:509), like is done in the following sentences: Students should be required to study art and music because these are compulsory subjects, Our generation is different from that of our parents because we do things in other ways, I watch TV every day because it has become an inseparable part of my life.

Still another common error is a hasty generalization, when the writer jumps to conclusions without weighing all the evidence or only basing on one or two examples. The paragraph below is a case in point:

I would buy a business. If you want to earn stable income, you must have your own business. Those who once considered this as a worthwhile investment are successful businessmen today. So I would put the money in setting up and developing a company of my own. 
The writer stereotypes all business people as successful. Meanwhile, the fact that many people around have succeeded in running their businesses doesn't guarantee that any business is sure to be profitable. The writer relies on the successful experience of a few acquaintances but fails to assess the validity of the judgment or provide any other logical explanation.

\section{Conclusion}

We all make reasoning errors in everyday situations. However, introducing EFL learners to the simple strategies discussed above and teaching them to weigh their arguments and assess their value with the help of logical reasoning will considerably improve their writing skill. On the contrary, unsound reasoning can lead to wrong conclusions and undermine the credibility of judgments. It should definitely receive due attention in the test preparation process.

Simultaneously, the extensive reading of model essays is not enough for students to acquire, rather than learn, the combined skill of reasoning and writing logically. Logical reasoning deals with both rational progression of ideas and various types of logical arguments. It not only means connecting sentences in the right sequence but also using valid and sound arguments to reach sufficiently credible conclusions. It is our firm belief that reading and practice need to be supplemented by a deep analysis of both models and one's own essays. This activity will develop the learners' ability to analyze and evaluate, rationalize and make inferences. It will promote critical reading and thinking skills, as well as the ability to eliminate irrelevant issues and avoid reasoning fallacies.

\section{References:}

1. Bradford, A. (2015, March 23) Deductive Reasoning vs. Inductive Reasoning. Available at: <http://www.livescience.com/21569-deduction-vsinduction.html $>$ [Accessed August 2015]

2. Brutyan, G.A. (1998) Logic. Yerevan: "Gitutyun" Publishing House.

3. Heiserman, D.L (Ed.) (2012, June 29) Thinking \& Writing. A First Course in Critical Writing and Communication. Available at: 
$<$ http://www.waybuilder.net/sweethaven/English/CritComm01/?iNum=030> [Accessed August 2015].

4. Kennedy, X.J.; Kennedy, D.M.; Aaron, J.E. (2003) The Bedford Reader. Boston: Bedford/St. Martin's.

5. Teays, W. (2003) Second Thoughts: Critical Thinking for a Diverse Society. Boston: McGraw Hill Companies, Inc.

\section{Sources of Data:}

1. (2011) Cambridge IELTS 8. Examination papers from University of Cambridge ESOL Examinations. Cambridge: CUP.

2. Hudon, E.; Clayton, I.; Weissgerber, K.; Allen, P. (2006) TOEFL IBT. 20072008 Edition. New York: Kaplan, Inc.

3. Lougheed, L. (2004) How to Prepare for the Computer-Based TOEFL Essay. New York: Barron's Educational Series.

4. (2013) Official TOEFL IBT Tests. Vol. 1. N.Y.: McGraw Hill Companies, Inc.

\section{9puuln lunuph unpưumpuauluma uinph nnn2 unuGióGuhuunlnnıjnıGGiłph 2nıp2}

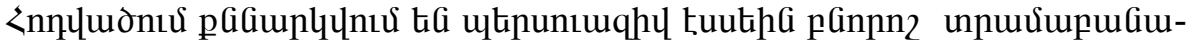

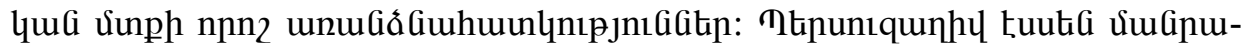

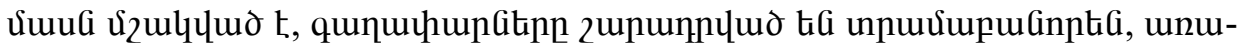

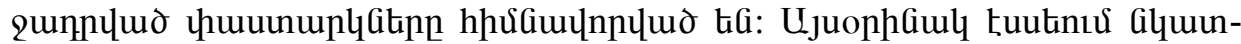

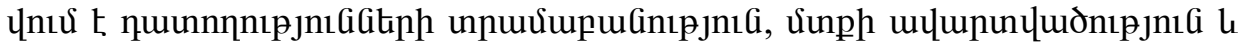

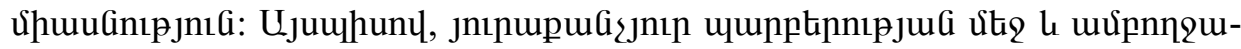

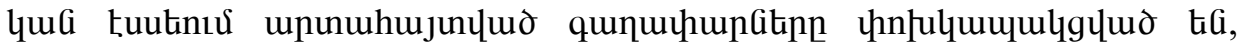

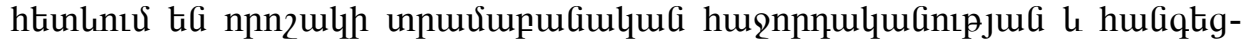

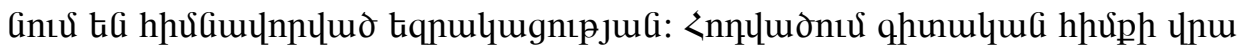

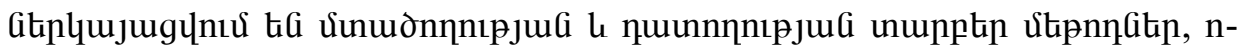

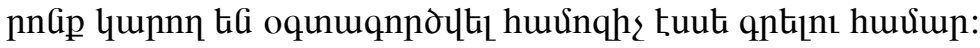

